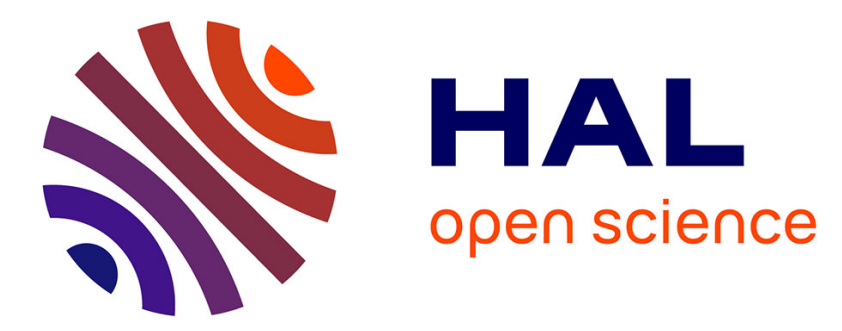

\title{
Maxima and minima of the displacement components for the Lamb modes
}

Farid Chati, Fernand Léon, Dominique Décultot, Gérard Maze

\section{To cite this version:}

Farid Chati, Fernand Léon, Dominique Décultot, Gérard Maze. Maxima and minima of the displacement components for the Lamb modes. Journal of the Acoustical Society of America, 2011, 129 (4), pp.1899-1904. 10.1121/1.3559702 . hal-01933838

\section{HAL Id: hal-01933838 \\ https://hal.science/hal-01933838}

Submitted on 28 Jun 2019

HAL is a multi-disciplinary open access archive for the deposit and dissemination of scientific research documents, whether they are published or not. The documents may come from teaching and research institutions in France or abroad, or from public or private research centers.
L'archive ouverte pluridisciplinaire $\mathbf{H A L}$, est destinée au dépôt et à la diffusion de documents scientifiques de niveau recherche, publiés ou non, émanant des établissements d'enseignement et de recherche français ou étrangers, des laboratoires publics ou privés. 


\title{
Maxima and minima of the displacement components for the Lamb modes
}

\author{
Farid Chati, ${ }^{a)}$ Fernand Léon, Dominique Décultot, and Gérard Maze \\ Laboratoire Ondes et Milieux Complexes, LOMC FRE CNRS 3102, Université du Havre, Place Robert \\ Schuman, BP 4006, Le Havre 76610, France
}

This paper revisits the vanishing of the transverse component of the particle displacement vector in free surfaces of an isotropic homogeneous plate, for both symmetric and antisymmetric Lamb waves. Drawing on well-known analytical expressions from Viktorov's book [(1967) Rayleigh and Lamb Waves: Physical Theory Applications, Chap. II, pp. 67-121], two distinct frequency-thickness product expressions, in cases where this vanishing occurs, are derived: one for the symmetric modes and another for the antisymmetric modes. At these frequency-thickness products, phase and group velocities have appreciable values which are discussed herein. It appears that these velocities depend on the transverse bulk wave velocity only. This is the specific condition of the Lamé modes. Moreover, theoretical and experimental investigations of displacements in the surface of a plate in air have been carried out. The theoretical part shows that the normal and transverse displacements have, respectively, a local maximum and a local minimum in the vicinity of these frequency-thickness products. The experimental part corroborates the presence of the local maximum of the $S_{0}$ Lamb mode for various materials.

\section{INTRODUCTION}

Pilarsky et al. have demonstrated that the normal component of the particle displacement vector in free surfaces of a plate, for nonzero-order symmetric Lamb waves, vanishes when the phase velocity attains the velocity of the bulk longitudinal waves. ${ }^{1}$ These authors have also shown that the group velocity is independent of the mode order. These features bear some significant practical importance in the nondestructive testing (NDT) of the fluid filled pipes. Indeed, energy leakage into the fluid can be substantially reduced due to the vanishing of the normal surface displacement. Certain authors like Hay et al. and Lowe et al. have extensively harnessed this specificity in their works devoted to pipe inspection. ${ }^{2-4}$ In a recent paper, ${ }^{5}$ Royer et al. have investigated the variation of dispersion curves of Lamb modes as a function of the Poisson ratio $v$. They show that branches of curves for phase velocities higher than $C_{T} \sqrt{2}$ (where $\mathrm{C}_{T}$ is the transverse bulk wave velocity) are very sensitive to the Poisson ratio. Conversely, in the case where the phase velocity is lower than $\mathrm{C}_{T} \sqrt{2}$, only a weak dependence on this ratio is observed.

In this paper we show that the transverse component of the particle displacement vector in free surfaces of a plate for both symmetric and antisymmetric Lamb modes can also vanish. Analytic expressions of the frequency-thickness products, $f_{s} e$ (for the symmetric modes) and $f_{a} e$ (for the antisymmetric modes), are determined when the transverse component is nil. This specific condition is the one of the Lamé modes described in the Graff's book. ${ }^{6}$ Just as in the works

\footnotetext{
a) Author to whom correspondence should be addressed. Electronic mail: farid.chati@univ-rouen.fr
}

by Pilarsky et al., particular attention is paid herein on the group velocities and their expressions are written.

Further, theoretical and experimental investigations of the normal component of displacement in the surface of a plate in air have been carried out. The aim of these additional investigations is to demonstrate that the normal displacement in the surface reaches a maximum for specific values of frequency-thickness products $f_{s} e$ and $f_{a} e$. This phenomenon is of particular interest for the NDT achieved by means of a setup using a laser interferometer. This measurement method may be applied to estimate the transverse velocity, from the observation of the normal component in the surface of the plate.

\section{THEORETICAL ANALYSIS: LAMÉ MODES IN A PLATE IN VACUUM}

This section recalls the particular features of the Lamé modes described in the Graff's book. ${ }^{6}$ Using Viktorov's notation, ${ }^{7}$ expressions of the transverse components of the displacement of antisymmetric and symmetric Lamb waves can be written as,

$$
\begin{aligned}
& U_{s}=\mathrm{D}\left(\frac{\left(k_{s}^{2}+s_{s}^{2}\right) \operatorname{sh}\left(s_{s} d\right)}{2 q_{s} \operatorname{sh}\left(q_{s} d\right)} \operatorname{ch}\left(q_{s} z\right)-s_{s} \operatorname{ch}\left(s_{s} z\right)\right) e^{i k_{s} x} \\
& U_{a}=\mathrm{C}\left(\frac{\left(k_{a}^{2}+s_{a}^{2}\right) \operatorname{ch}\left(s_{a} d\right)}{2 q_{a} \operatorname{ch}\left(q_{a} d\right)} \operatorname{sh}\left(q_{a} z\right)-s_{a} \operatorname{sh}\left(s_{a} z\right)\right) e^{i k_{a} x}
\end{aligned}
$$

where

$$
\begin{aligned}
& q_{s, a}^{2}=k_{s, a}^{2}-k_{L}^{2}, \\
& s_{s, a}^{2}=k_{s, a}^{2}-k_{T}^{2},
\end{aligned}
$$


and $d$ is the half thickness of the plate. $k_{L}$ and $k_{T}$ are, respectively, the longitudinal and transverse wavenumbers. $\mathrm{C}$ and $\mathrm{D}$ are the constants. The harmonic time dependence term $e^{-\mathrm{i} \omega \mathrm{t}}$ is omitted in the equations.

The transverse component of the displacement in free surfaces of an isotropic homogeneous plate vanishes when the phase velocity of Lamb waves reaches the value

$$
\mathrm{C}_{p h}=\mathrm{C}_{T} \sqrt{2}
$$

where $\mathrm{C}_{T}$ is the celerity of the bulk transverse waves,

$$
\lim _{k_{s, a} \rightarrow k_{T} / \sqrt{2}} U_{s, a}(z)=0, \text { for } z= \pm d .
$$

For this particular phase velocity, the Lamb modes are called the Lamé modes.

To prove the validity of expression in Eq. (6), it is necessary to determine the two frequency-thickness products $f_{s} e$ and $f_{a} e$ at which the $p$ th antisymmetric and the $p$ th symmetric modes have phase velocity equal to $\mathrm{C}_{T} \sqrt{2}(e=2 d, e$ is the thickness of the plate). To this end, the characteristic equations $\Omega_{s}=0$ and $\Omega_{a}=0$, associated with these modes, are considered. ${ }^{7}$

The obtained frequency-thickness products $f_{s} e$ and $f_{a} e$ are expressed as follows:

$$
\begin{aligned}
& \left(f_{s} e\right)_{P}=\frac{(2 p+1) \mathrm{C}_{T}}{\sqrt{2}}, \text { for } p=0,1,2,3, \ldots, \\
& \left(f_{a} e\right)_{P}=p \mathrm{C}_{T} \sqrt{2}, \text { for } p=1,2,3, \ldots .
\end{aligned}
$$

Order $p=0$ is excluded from expression in Eq. (8) because, at zero frequency, no mode with a phase velocity equal to $\mathrm{C}_{T} \sqrt{2}$ exists.

Substituting Eq. (7) into Eq. (1) and Eq. (8) into Eq. (2), the limits of displacement of transverse components $U_{s}$ and $U_{a}$ when the phase velocity tends toward $\mathrm{C}_{T} \sqrt{2}$ may be written as,

$$
\begin{aligned}
& \lim _{k_{s, a} \rightarrow k_{T} / \sqrt{2}} U_{s}(z)=\mathrm{D} \frac{k_{T}}{\sqrt{2}} \cos \left(\frac{(2 p+1) \pi}{2 d} z\right) e^{i(k x-\pi / 2)} \\
& \lim _{k_{s, a} \rightarrow k_{T} / \sqrt{2}} U_{a}(z)=\mathrm{C} \frac{k_{T}}{\sqrt{2}} \sin \left(\frac{p \pi}{d} z\right) e^{i k x}
\end{aligned}
$$

Therefore, at the surface of a plate (i.e., when $z= \pm d$ ), these two components become nil.

Group velocities can be found from the following implicit form, 1,8

$$
C_{g s, a}=-\frac{\partial \Omega_{s, a} / \partial k}{\partial \Omega_{s, a} / \partial \omega} .
$$

As regards symmetric modes, the relation for the group velocity found in the limit case where $\mathrm{C}_{p h} \rightarrow \mathrm{C}_{T} \sqrt{2}$ and for $f_{s} e$ products given by Eq. (7), is expressed as follows:

$$
\lim _{\substack{k \rightarrow k_{T} / \sqrt{2} \\ f e \rightarrow\left(f_{s} e\right)_{p}}} \mathrm{C}_{g s}=\frac{\mathrm{C}_{T}}{\sqrt{2}}\left(\frac{2-k_{T}^{2} q_{S} d \operatorname{th}\left(q_{S} d\right)}{1-k_{T}^{2} q_{S} d \operatorname{th}\left(q_{S} d\right)}\right)
$$

and, for the antisymmetric modes, the relation in the same limit case for $f_{a} e$ products given by Eq. (8), is expressed as follows:

$$
\lim _{\substack{k \rightarrow k_{T} / \sqrt{2} \\ f e \rightarrow(f a e) p}} \mathrm{C}_{g a}=\frac{\mathrm{C}_{T}}{\sqrt{2}}\left(\frac{2-k_{T}^{2} q_{a} d \operatorname{coth}\left(q_{a} d\right)}{1-k_{T}^{2} q_{a} d \operatorname{coth}\left(q_{a} d\right)}\right)
$$

\section{THEORETICAL AND EXPERIMENTAL ANALYSES: A PLATE IN AIR}

In this section, we assume isotropic and homogeneous plates of thickness $e$ placed in air. Two plates made of different materials are considered: Duraluminum and polymethyl methacrylate (PMMA). The standard physical parameters used in our computations are, ${ }^{9-11}$

-Duraluminum: $e=5 \mathrm{~mm}, \rho=2765 \mathrm{~kg} / \mathrm{m}^{3}, \mathrm{C}_{L}=6440 \mathrm{~m} / \mathrm{s}$,

$$
\mathrm{C}_{T}=3113 \mathrm{~m} / \mathrm{s} \text {. }
$$

-PMMA: $\quad e=4.2 \mathrm{~mm}, \rho=1180 \mathrm{~kg} / \mathrm{m}^{3}, \mathrm{C}_{L}=2690 \mathrm{~m} / \mathrm{s}$,

-Air:

$$
\mathrm{C}_{T}=1340 \mathrm{~m} / \mathrm{s} \text {. }
$$

$$
\rho=1.293 \mathrm{~kg} / \mathrm{m}^{3}, \mathrm{C}_{L}=331.45 \mathrm{~m} / \mathrm{s} \text {. }
$$

For these two materials, we pay particular attention on the investigation of the first two Lamb modes which propagate along the plate in air, i.e. the $\mathrm{A}_{1}$ mode and the $\mathrm{S}_{0}$ mode. Contrary to the case of a plate in vacuum, it is possible to calculate the absolute displacements of these waves in the interface of a plate placed in a fluid, for example in air. These displacements are expressed by the following relations:

$$
\begin{aligned}
& U_{n}=\frac{\partial \varphi_{s, a}^{*}}{\partial x}-\frac{\partial \psi_{s, a}^{*}}{\partial z} \\
& U_{T}=\frac{\partial \varphi_{s, a}^{*}}{\partial x}+\frac{\partial \psi_{s, a}^{*}}{\partial z},
\end{aligned}
$$

where the normal displacement component $U_{n}$ and the transverse displacement component $U_{T}$ are deduced from the scalar potentials $\varphi_{s, a}^{*}$ and the vector potentials $\psi_{s, a}^{*}$ defined by Izbicki et al. ${ }^{12}$ Moreover, the frequency-thickness products of these two Lamb modes for a plate placed in vacuum are very close to those of a plate placed in air because of the low loading of this fluid. ${ }^{12}$ Thus, analytical expressions in Eqs. (7) and (8) are applied to determine fe products for which the transverse motions of the Lamb modes are nil in the frequency range of $0-12 \mathrm{MHz} \mathrm{mm}$. From these results, the elastic theory is applied to calculate transverse and normal displacements in the interface of the plate placed in air, in the vicinity of these $f e$ products.

The experimental setup is presented in Fig. 1. Measurements are made on rectangular plates of $25 \mathrm{~mm}$ length, 20 $\mathrm{mm}$ width. The thicknesses of the duraluminum and the PMMA plates are, respectively, 5 and $4.2 \mathrm{~mm}$. These plates are, in turn, placed vertically and fixed onto a piezoelectric transducer. The transducer excites a section of one of the edges of the plate to generate the $S_{0}$ Lamb mode. In order to 


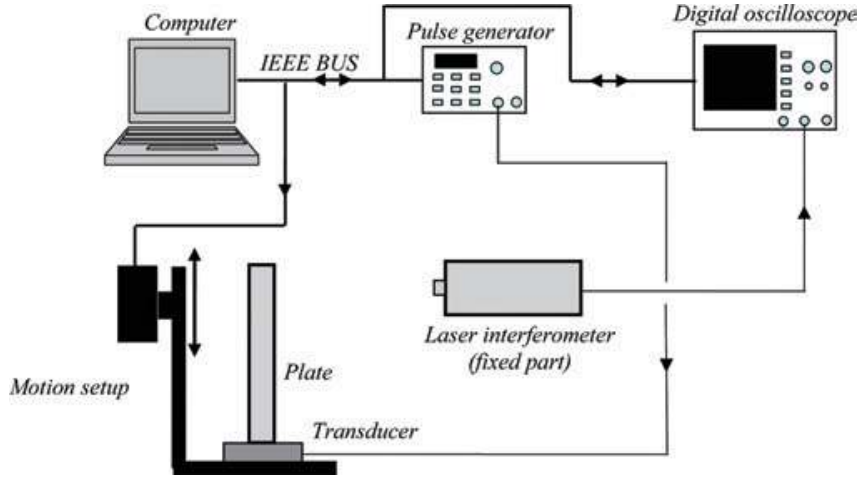

FIG. 1. (Color online) Experimental setup.

ensure proper ultrasound coupling, a Metalscan gel layer is applied on the transducer/plate contact surface. The setup is rendered vertically mobile by means of a motion mechanism, which allows the measuring of the normal displacement at various vertical positions in the plate surface. The excitation of the $S_{0}$ mode is achieved by using the broadband piezoelectric transducer Panametrics 401 with a central frequency of $500 \mathrm{kHz}$ (see Fig. 1). The transducer is itself excited by a broadband short pulse delivered from a pulse generator. The detection of the signal is achieved using a laser interferometer (BMI heterodyne probe SH140) to measure the normal displacement in the surface of the plate. Measurements are made at a series of equally spaced positions along the plate with a step interval of $0.1 \mathrm{~mm}$ over a length of $50 \mathrm{~mm}$. The recorded signals are averaged out and displayed on a Lecroy digital oscilloscope (Fig. 1). Thereafter, the signal obtained from these recordings is transmitted and saved in a computer via the IEEE bus, for further numerical processing. This computer also serves as a driving and controlling tool for the movements of the plate.

\section{RESULTS AND DISCUSSION}

This section presents some distinctive features of the symmetric and antisymmetric Lamb modes when phase velocity attains $\mathrm{C}_{T} \sqrt{2}$. This particular condition of mode propagating in the free isotropic plate is the one of the Lamé modes. The studied characteristics are the frequency-thickness product, the group velocity, and the amplitudes of displacement in the surface of the duraluminum plate.

Figure 2 presents a typical plot of phase velocity dispersions of the Lamb modes as a function of the frequency-thickness product in the range of $0-12 \mathrm{MHz} \mathrm{mm}$. The symmetric modes are labeled as $\mathrm{S}_{0}, \mathrm{~S}_{1}, \mathrm{~S}_{2}$ and the antisymmetric modes are labeled as $\mathrm{A}_{1}, \mathrm{~A}_{2}$. The frequency-thickness products are labeled as $\left(f_{s} e\right)_{0},\left(f_{a} e\right)_{1}$, $\left(f_{s} e\right)_{1},\left(f_{a} e\right)_{2},\left(f_{s} e\right)_{2}$ which correspond to values where the mode phase velocity is equal to $\mathrm{C}_{T} \sqrt{2}$. The interval between two successive frequency-thickness products is equal to $\mathrm{C}_{T} / \sqrt{2}$. This first particularity is easily verified by computing the difference between Eqs. (7) and (8) as illustrated in Sec. II.

Figures 3 and 4 represent, respectively, the dispersion curves of phase and group velocities of the $S_{0}$ and $A_{1}$ Lamb modes for the frequency-thickness products $\left(f_{s} e\right)_{0}$ and $\left(f_{a} e\right)_{1}$ for a duraluminum plate. The two figures show that the group velocity of these two modes is very close to $C_{T} / \sqrt{2}$. This second feature is generalized to any other mode order by using the two dispersion group relations presented in Eqs. (12) and (13), for fe products given by Eqs. (7) and (8). Indeed, it appears, clearly, that the group velocities $\mathrm{C}_{g a}$ and $\mathrm{C}_{g s}$ in the expressions of Eqs. (12) and (13) tend toward $\mathrm{C}_{T} / \sqrt{2}$ as the mode order rises. As regards the lowest orders such as the modes $S_{0}$ and $A_{1}$, this remains true insofar as the thickness of the plate is not too big. In the case of the studied plate of thickness $5 \mathrm{~mm}$, the absolute relative error of

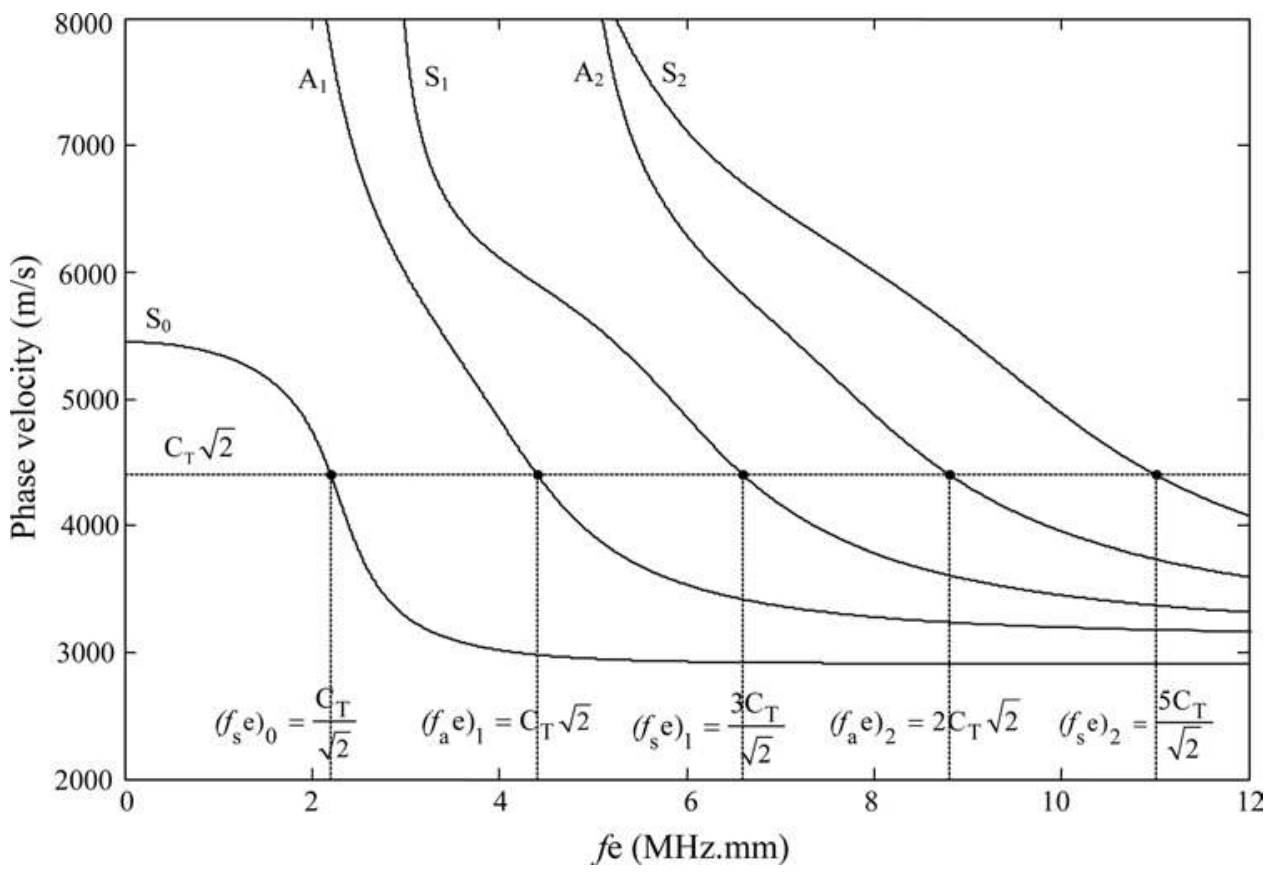

FIG. 2. Dispersion curves of the phase velocity of Lamb modes in a duraluminum plate of thickness $5 \mathrm{~mm}$. 


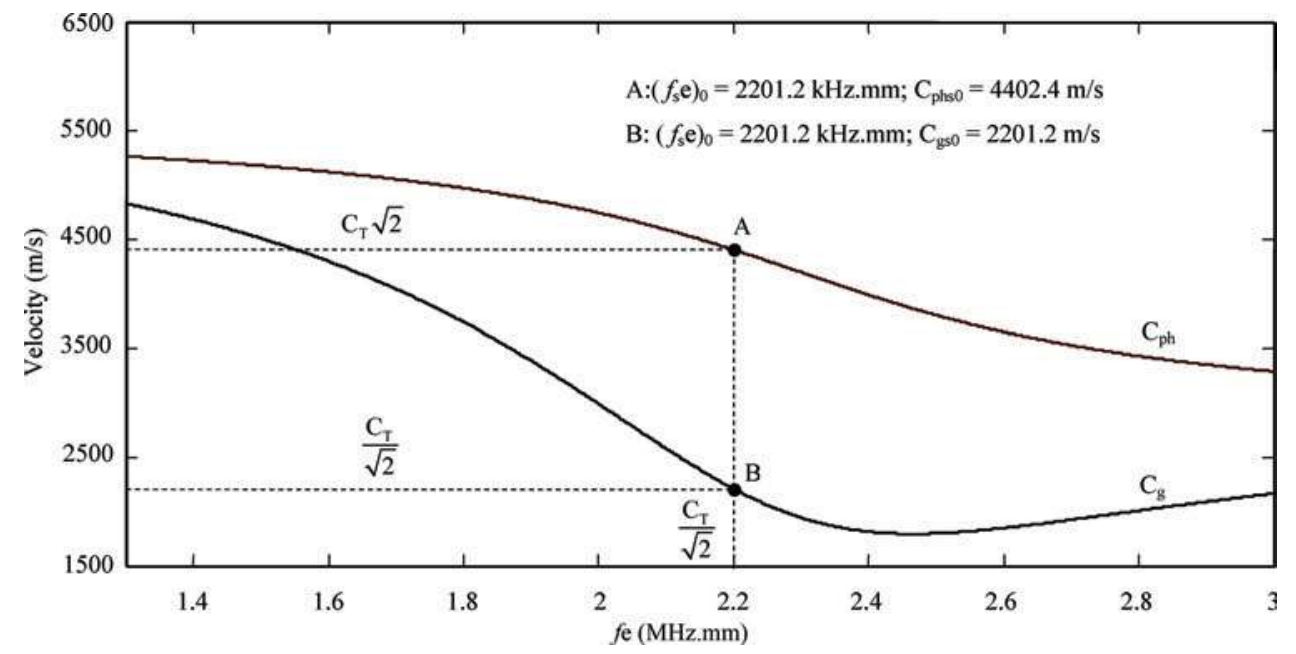

FIG. 3. (Color online) Dispersion curves of the group and phase velocities of $S_{0}$ mode in a duraluminum plate of thickness $5 \mathrm{~mm}$.

velocity between $\mathrm{C}_{g s 0}$ (group velocity of $\mathrm{S}_{0}$ ) and $\mathrm{C}_{T} / \sqrt{2}$ is less than $7 \times 10^{-5 \%}$ and the error between $C_{g a 1}$ (group velocity of $\mathrm{A}_{1}$ ) and $\mathrm{C}_{T} / \sqrt{2}$ is less than $9 \times 10^{-6 \%}$. We deduce therefrom that the group velocity becomes practically independent of the mode order. The phase-velocity $\times$ group-velocity product is then close to the square of the transverse velocity. Moreover, as it is pointed out by Pagneux ${ }^{13}$ and Zernov et al., ${ }^{14}$ the $\mathrm{S}_{0}$ Lamé mode is a necessary condition for the existence of the edge resonance. Indeed these authors have shown that this trapped mode (edge resonance) is due to a decoupling between the $S_{0}$ Lamb mode and the higher order evanescent modes.

In order to illustrate the third and last feature, the calculations of the normal displacement component $U_{n}$ and the transverse displacement component $U_{T}$ have been realized for a duraluminum plate in air. Both $U_{n}$ and $U_{T}$ are normalized by the local maximum of $U_{n}$ in the considered frequency window. Figures 5(a) and 5(b) are, respectively, the plots of $U_{n}$ and $U_{T}$ for the $\mathrm{S}_{0}$ Lamb mode in the surface of the plate. These plots clearly show that component $U_{n}$ has a local maximum and the component $U_{T}$ has a local minimum in the vicinity of a particular frequency-thickness product $\left(f_{s} e\right)_{0}$ (i.e., when $\left(f_{s} e\right)_{0}=\mathrm{C}_{T} / \sqrt{2}$ ). The same phenomena are observed in Figs. 6(a) and 6(b) for the $A_{1}$ Lamb mode but, this time, in the vicinity of the frequency-thickness product $\left(f_{a} e\right)_{1}$ (i.e., when $\left(f_{a} e\right)_{1}=C_{T} \sqrt{2}$ ). We also note that transverse displacement components of modes $S_{0}$ and $A_{1}$ are very weak though not nil at, respectively, $\left(f_{s} e\right)_{0}$ and $\left(f_{a} e\right)_{1}$ because the plate is air loaded. Therefore, the search for these minimum and maximum values could have a significant practical meaning, making it possible to obtain an estimation of the transverse velocity of a material. Indeed, the associated frequency-thickness products being dependent only on the transverse velocity $\mathrm{C}_{T}$, the knowledge of these values enables us to estimate the value of $\mathrm{C}_{T}$.

The measurement method described in details in Sec. III is used to obtain the normal displacement in the surface of the plate. Measured time signals allow us to obtain a representation of the wavenumber $k$ as a function of frequency $f$ (dispersion curve), after performing a 2D Fourier transform ${ }^{15,16}$ on the signal. Figure 7 shows such presentation for the $S_{0}$ mode. This figure provides amplitude shading presentation in which the lighter the shading the higher the amplitude. The $\mathrm{S}_{0}$ mode at the frequency $\left(f_{s}\right)_{0}=454.7 \mathrm{kHz}$ and wavenumber $k=667.3 \mathrm{~m}^{-1}\left(\mathrm{C}_{p h}=4281.4 \mathrm{~m} / \mathrm{s}\right)$ dominates the normal displacement in the frequency range of 300-700 $\mathrm{kHz}$. From the expression in Eq. (5), we deduce the value of transverse velocity of the bulk wave, which is equal to 3028

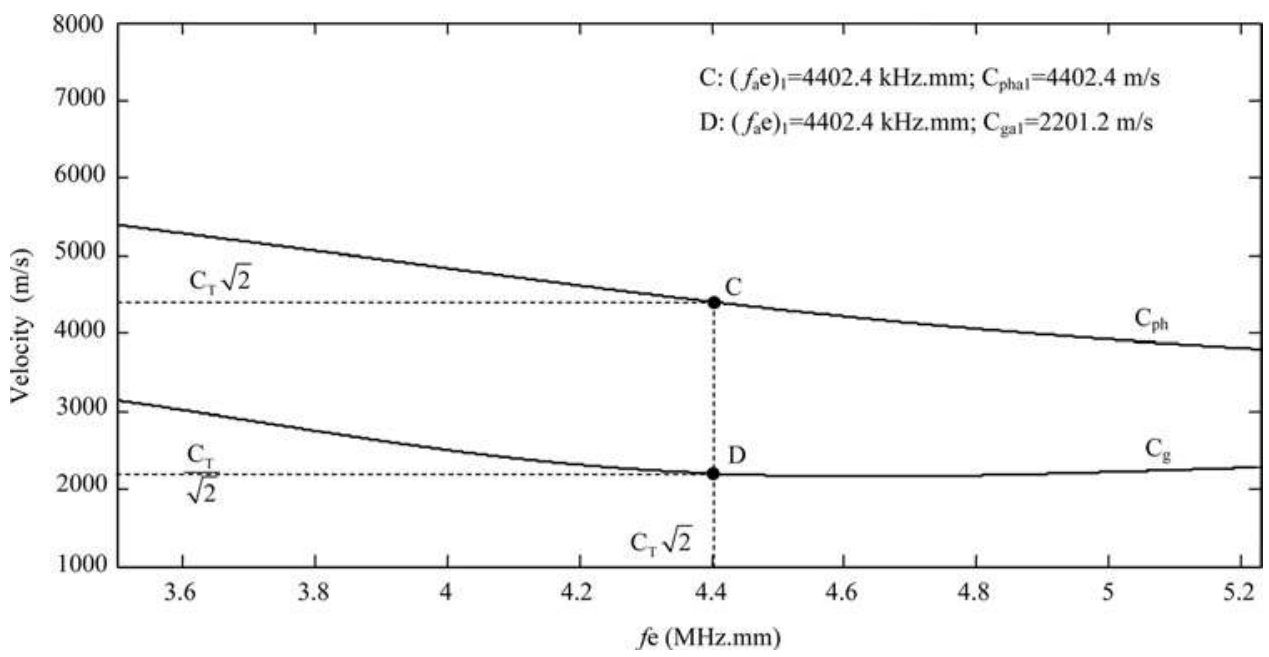

FIG. 4. Dispersion curves of the group and phase velocities of $A_{1}$ mode in a duraluminum plate of thickness $5 \mathrm{~mm}$. 

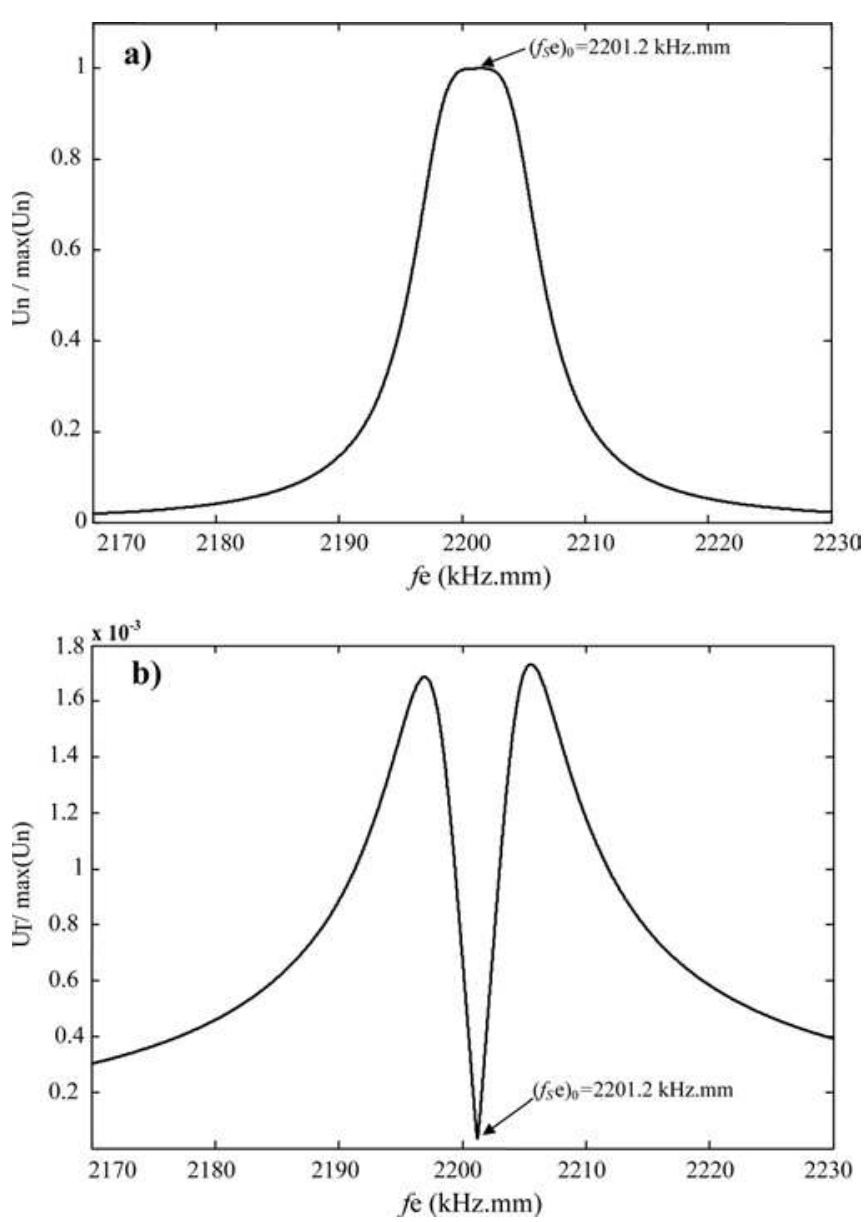

FIG. 5. (a) Normal displacement component of the $S_{0}$ mode in the surface of a duraluminum plate of thickness $5 \mathrm{~mm}$. (b) Transverse displacement component of the $S_{0}$ mode in the surface of a duraluminum plate of thickness $5 \mathrm{~mm}$.

$\mathrm{m} / \mathrm{s}$. The same experimental work has been achieved for a PMMA plate. The main results are presented in Table I.

In the case of duraluminum, the estimated value of $\mathrm{C}_{T}$ differs slightly from the standard parameter $\mathrm{C}_{T}$ (see Table1): the transverse velocity error is less than $3 \%$. This can partly be explained by the non-uniformity of the plate thickness and partly by the type of duraluminum used experimentally which is different from the standard one. For PMMA, the estimated value of $\mathrm{C}_{T}$ is also close to theoretical results: The transverse velocity error is less than $3 \%$.

\section{CONCLUSION}

The vanishing of the transverse displacement components of symmetric and antisymmetric Lamb waves in a free plate has been revisited. This occurs when the phase velocities are equal to $C_{T} \sqrt{2}\left(\mathrm{C}_{T}\right.$ is the velocity of bulk transverse waves). Thus, two analytical expressions of the frequencythickness product are given: One for the symmetric waves $\left(f_{s} e\right)_{\mathrm{p}}$ and another for antisymmetric waves $\left(f_{a} e\right)_{\mathrm{p}}$ (index $p$ is the mode order). Then, two formulations of the group velocity have been established when the phase velocity tends toward $C_{T} \sqrt{2}$ and the frequency-thickness product toward $\left(f_{s} e\right)_{p}$ or $\left(f_{a} e\right)_{p}$. From the results obtained, it was noted that two distinctive features for the symmetric or antisymmetric
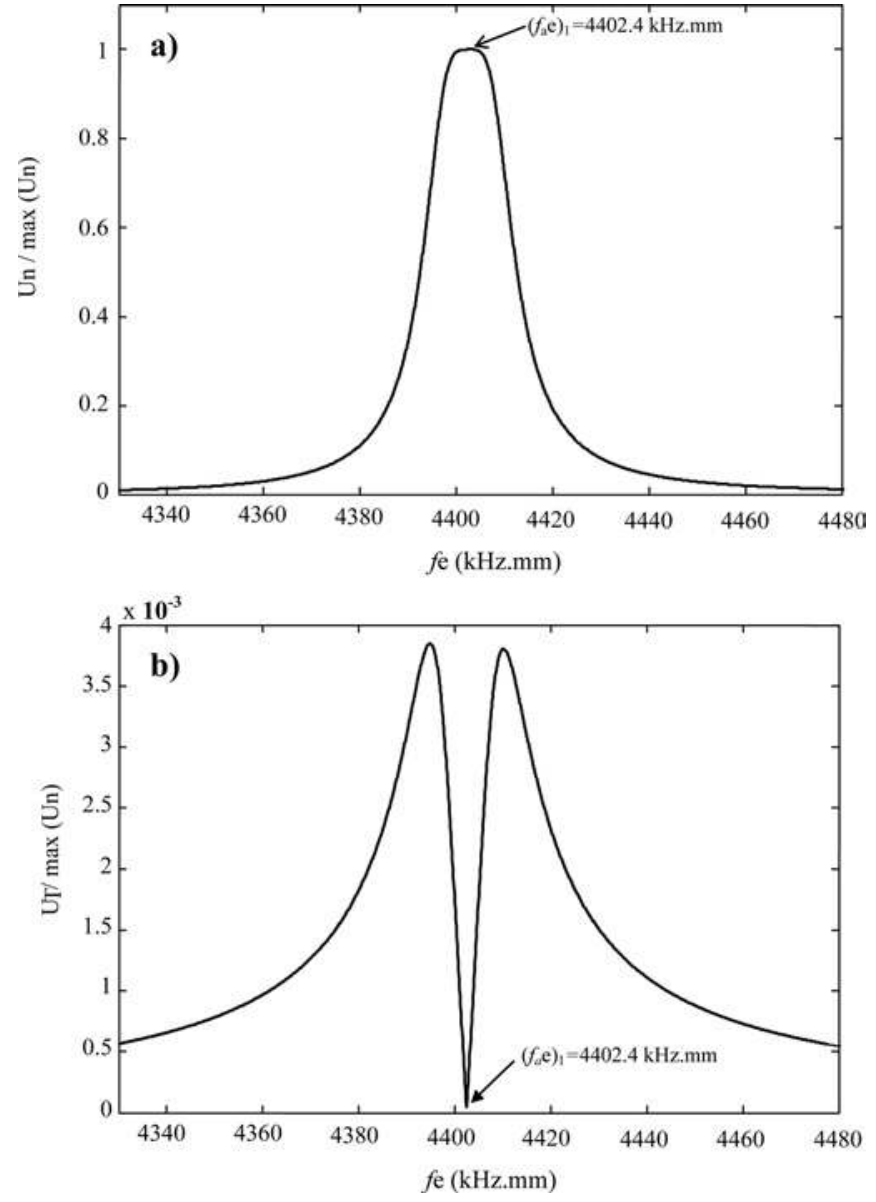

FIG. 6. (a) Normal displacement component of the $A_{1}$ mode in the surface of a duraluminum plate of thickness $5 \mathrm{~mm}$. (b) Transverse displacement component of the $\mathrm{A}_{1}$ mode in the surface of a duraluminum plate of thickness $5 \mathrm{~mm}$.

Lamb waves stand out clearly when the phase velocity is equal to $C_{T} \sqrt{2}$ : (i) the interval between two successive frequency-thickness products is always equal to $\mathrm{C}_{T} / \sqrt{2}$ and (ii) their group velocities tend toward the limit $C_{T} / \sqrt{2}$.

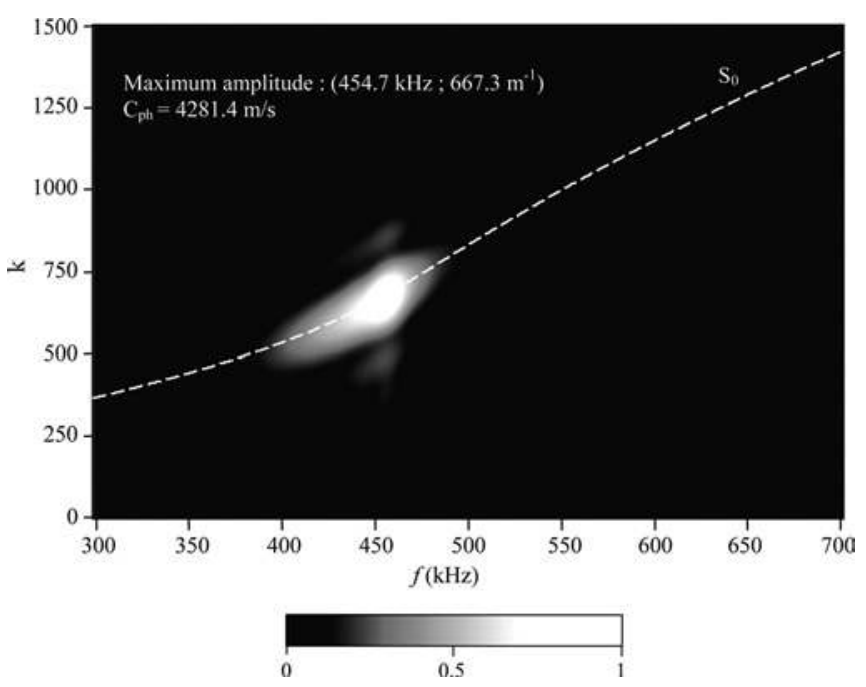

FIG. 7. Modulus of the space-time Fourier transform of experimental time signals of the $S_{0}$ mode in the surface of the duraluminum plate of thickness $5 \mathrm{~mm}$. White dashed line: theoretical trajectory of the $\mathrm{S}_{0}$ mode. 
TABLE I. Estimation of the transverse velocity $\mathrm{C}_{T}$ of the two materials: duraluminum and PMMA.

\begin{tabular}{lcc}
\hline \hline Material plate & Duraluminum & PMMA \\
\hline Experimental frequency $\left(f_{S} e\right)_{0}(\mathrm{kHz})$ & 454.7 & 211.2 \\
Estimated phase velocity $\mathrm{C}_{p h}(\mathrm{~m} / \mathrm{s})$ & 4281.4 & 1875.4 \\
Estimated transverse velocity $\mathrm{C}_{T}(\mathrm{~m} / \mathrm{s})$ & 3028 & 1326 \\
Standard transverse velocity $\mathrm{C}_{T}(\mathrm{~m} / \mathrm{s})($ Refs. 9, 11) & 3113 & 1340 \\
\hline \hline
\end{tabular}

Moreover, an additional theoretical study of absolute normal displacements of $S_{0}$ and $A_{1}$ waves in the surface of an air loaded duraluminum plate has been carried out. This shows that the normal displacements have a local maximum in the vicinity of their respective frequency-thickness products $\left(f_{s} e\right)_{0}=C_{T} / \sqrt{2}$ and $\left(f_{a} e\right)_{1}=C_{T} \sqrt{2}$. This happens when their absolute transverse displacements have a local minimum. An experimental investigation has allowed us to corroborate this third feature for the $\mathrm{S}_{0}$ wave. This has been achieved for both duraluminum and PMMA plates. The velocity of the bulk waves $\mathrm{C}_{T}$, of each of these materials, has been estimated with a good experimental accuracy.

\section{ACKNOWLEDGMENTS}

The authors are grateful to Dr. J. G. Chiumia and the reviewers for their careful reading of this manuscript and useful suggestions.

\footnotetext{
${ }^{1}$ A. Pilarsky, J. J. Ditri, and J. L. Rose, "Remarks on symmetric Lamb waves with dominant longitudinal displacements," J. Acoust. Soc. Am. 93, 2228-2230 (1993).
}

${ }^{2}$ T. R. Hay and J. R. Rose, "Fouling detection in the food industry using ultrasonic guided waves," Food Control 14, 481-488 (2003).

${ }^{3}$ T. R. Hay and J. R. Rose, "Flexible PVDF comb transducers for excitation of axisymmetric guided waves in pipe," Sens. Actuators A 100, 18-23 (2002).

${ }^{4}$ M. J. S. Lowe, D. N. Alleyne, and P. Cawley "Defect detection in pipes using guided waves," Ultrasonics 36, 147-154 (1998).

${ }^{5}$ D. Royer, D. Clorennec, and C. Prada, "Lamb mode spectra versus the Poisson ratio in a free isotropic elastic plate," J. Acoust. Soc. Am. 125, 3683-3687 (2009)

${ }^{6}$ K. F. Graff, Wave Motion in Elastic Solids (Dover Publications, New York, 1991), Chap. 8, pp. 462-463.

${ }^{7}$ I. A. Viktorov, Rayleigh and Lamb Waves: Physical Theory Applications (Plenum, New York, 1967), Chap. II, pp. 67-121.

${ }^{8}$ J. L. Rose, Ultrasonic Waves in Solid Media (Cambridge University Press, 1999), Chap. 8, pp. 123.

${ }^{9}$ F. Léon, F. Chati, and J. M. Conoir, "Modal theory applied to the acoustic scattering by elastic cylinders of arbitrary cross section," J. Acoust. Soc. Am. 116, 686-692 (2004).

${ }^{10}$ Handbook of Chemistry and Physics, 50th, edited by R. C. Weast (The Chemical Rubber Company, 1969-1970), p. E-43.

${ }^{11}$ L. S. Schuetz and W. G. Neubauer "Acoustic reflection from cylinders nonabsorbing and absorbing," J. Acoust. Soc. Am. 62, 513-517 (1977).

${ }^{12}$ J. L. Izbicki, G. Maze, and J. Ripoche, "Diffusion acoustique par une plaque élastique Acoustic scattering by an elastic plate" in La Diffusion Acoustique par des Cibles Élastiques de Forme Géométrique Simple, Théories et Experiences (Acoustic Scattering by Elastic Targets of Simple Geometrical Shape, Theories and Experiments) (N. Gespa, CEDOCAR Edition, Paris, 1987), Chap. 6 pp. 133-156.

${ }^{13} \mathrm{~V}$. Pagneux, "Revisiting the edge resonance for Lamb waves in a semi-infinite plate," J. Acoust. Soc. Am. 120, 649-656 (2006).

${ }^{14}$ V. Zernov, A. Pichugin, and J. Kaplunov, "Eigenvalue of semi-infinite elastic strip," Proc. R. Soc. London A 462, 1255-1270 (2006).

${ }^{15}$ D. Alleyne and P. Cawley, "A two-dimensional Fourier transform method for the measurement of propagating multimode signals," J. Acoust. Soc. Am. 89, 1159-1168 (1991).

${ }^{16}$ L. Martinez, "Nouvelles méthodes d'identication d'ondes de surfaces Etude de l'onde A sur une cible courbe (New methods of identification of surface waves-Study of the mode A on a curved target)" Ph.D. thesis, University of Le Havre, France (1998). 